\title{
Case Report - Possible Manufacturing Workplace Transmission of COVID-19
}

\author{
John H. Murphy ${ }^{1}$ \\ ${ }^{1}$ Dalla Lana School of Public Health, University of Toronto, Toronto, ON, Canada
}

\section{Corresponding author:}

John H Murphy, Dalla Lana School of Public Health, University of Toronto. 18 Wynford Drive, Suite 617, Toronto, Ontario Canada M3C $3 S 2$. 1-416-495-1314 | jh.murphy@mail.utoronto.ca | https://orcid.org/0000-0002-2364-519X

\begin{abstract}
A COVID-19 cluster was identified in an industrial manufacturing workforce soon after being recalled to the workplace following a furlough period. All cases in the cluster (21/85) were male, worked on one side of the plant, and took breaks and lunch together. All non-cases worked on the opposite side of the plant and similarly took breaks and lunch together. Review of the timing of return from furlough determined that workplace transmission was possible. However, a high percentage of the cases lived in apartment settings where high neighbourhood incidence rates were observed, whereas that was not the case for non-cases. The investigation illustrates the difficulties of distinguishing potential occupational from community transmission.
\end{abstract}

\section{KEYWORDS}

COVID-19, SARS CoV-2, Outbreak, Manufacturing, Occupational

\section{TRANSMISSION}

In Canada, there have been media reports of suspected workplace transmission of COVID-19 in meat-processing plants and in primary agricultural production facilities [1-4]. This report describes a rapid field epidemiological investigation of a COVID-19 cluster in an industrial manufacturing workforce and illustrates the difficulties of distinguishing possible occupational from community transmission.

In response to general concern over COVID-19, a manufacturer of upholstered products with 85 employees in southern Ontario ceased production and temporarily furloughed employees in mid-April 2020. This coincided with the implementation of emergency measures by the Government of Ontario for infection prevention and control, including the closure of non-essential business operations, schools, restaurants and most recreational facilities, and restrictions on sizes of social gatherings. With relaxation of certain emergency measures in mid-May, the employees were called back to the workplace to resume production, subject to certain work practice modifications described hereafter. Approximately 25\% of the employees returned initially, with three subsequent return waves between mid- and late May. While not mandated by law at the time, upon return to the workplace, the employer required all employees to wear either KN95 respirators, or pleated disposable medical procedure masks (technical filtration specifications for the procedure masks were not described by the mask manufacturer).

The company's one-storey 200,000 square foot production area has an open shop floor with high ceilings and mechanical ventilation. Prior to and following the furlough, all but a few employees worked all day at dedicated workstations separated from one another by at least 2 metres with most more distant. From the time of re-opening in mid-May, employees wore their masks or respirators for their entire shifts (single-day shift), except for morning and afternoon break periods and the lunch period, and the company implemented a range of surface contact disinfection and hand hygiene measures.

To facilitate distancing in the lunchroom, the workforce was divided into two groups to take time-staggered breaks (15 minutes in morning and again in the afternoon) and lunch (30 minutes midday). One group consisted of workers stationed on one side of the plant ("side A", where the initial stages of product manufacturing occurred) with the second group stationed at the other side ("side B", where final stages of manufacturing, packaging and shipping occurred). Chairs at lunchroom tables were organized to maximize distance (at least 2 metres) between occupants and use of lunchroom appliances had been prohibited. There were no other changes to work operations or employee schedules. An air-balancing 
report for the building indicated that the mechanical ventilation rate for the lunchroom was $2.5 \mathrm{cfm} / \mathrm{sf}$ total supply, $0.65 \mathrm{cfm} /$ sf outside air supply, which at the staggered occupancy levels provided outside air at a rate of at least $20 \mathrm{~cm} /$ person, well above the ASHRAE 62.1 recommended minimum of $5.12 \mathrm{~cm} /$ person [5].

On June 1, an employee with flu-like symptoms called the company to advise that he would be absent from work. He presented to the local public health unit and tested positive for SARS CoV-2 by nasal swab with polymerase chain reaction analysis. All employees voluntarily submitted to screening soon after, resulting in identification of 21 positive cases. All cases were male between the ages of 25 and 68 (mean 48, SD 12). Only two of those positive cases were known to be symptomatic (one being the employee calling in on June 1), and one reportedly required hospitalization. Sixty-two percent of the negative cases were male (all cases mean age 48, SD 12).

Spatial mapping of the work locations of positive cases determined that all were from side B of the plant (side B attack rate $\approx$ approximately $50 \%$, and overall workforce attack rate $=25 \%$ ). With minor exceptions, the only times that workers on sides A or B did not wear a mask or respirator was when using the lunchroom or the washrooms, which coincided with their scheduled cohorted breaks. Review of the May recall dates determined that three cases were identified three and four days after their return to work. Based upon a reported median, the COVID-19 incubation period of five days suggests those three cases likely were infected prior to their return to work [6]. The remaining cases returned from furlough for five to 16 calendar days prior to SARS CoV-2 screening, providing opportunity for three working days of exposure to two of the three individuals considered to be probable community cases. Given the five-day median and 11.5-day, 97\% upper limit incubation period for cases developing symptoms, it is possible that 18 of the 21 cases were a result of workplace transmission [6]. However, given that SARS CoV-2 virus shedding can persist for several weeks, it is possible the initial infection dates for all cases occurred during their furlough period [7]. The latter hypothesis was supported by a review of workforce home addresses which revealed that employees living in apartment units were over-represented among cases (odds ratio 2.4, $\mathrm{Cl} 0.9-6.5, \mathrm{p}=0.09$ ), and 11 of the cases lived in neighbourhoods having community case rates two to three times the overall average for their city.

If, as growing evidence and consensus opinion indicates, community transmission occurs primarily via inhalation of virus-laden respiratory aerosols in close proximity to an infected individual, the apparent sole opportunity for that to have occurred at this workplace was during break and lunch periods when the cohorted personnel were in close prolonged proximity to one another without use of respiratory protection. Given the established interpersonal distancing practices, and the improbability that all the SARS CoV-2 positive employees were in physical (i.e. touch) contact with one-another or common fomites, transmission via exposure to respiratory aerosols appears to be the most likely scenario in the instant case [8]. Introduction to the workplace by three community cases from side B of the plant with subsequent infection of several co-workers during breaks and lunch periods represents a plausible occupational transmission scenario.

However, the case over-representation among apartment dwellers and the elevated attack rates for neighbourhoods of half the cases points to community transmission and detection as a result of workplace-initiated testing as an equally plausible scenario. Outside of health, long-term care and workplace outbreak settings, it is not common for an entire workforce to be screened, and there are no other published reports to date describing the results of workforce-wide SARS CoV-2 screening other than in care settings. The $25 \%$ attack rate identified by workforce screening at the subject workplace may or may not be unusual, given the absence of comparators, and findings from serological surveys in major urban centres showing demographic subgroup prevalence rates as high as 30\% $[9,10]$.

As of June 9, 2020, approximately $2.5 \%$ of all swab PCR test results reported by Public Health Ontario were positive [11]. The attack rate revealed by workforce-wide testing in this case adds to the growing body of evidence that the prevalence of asymptomatic infection among working age persons may be considerably higher than suggested by data from swab PCR screening of selected target groups. From an occupational health perspective, the case may indicate that even with generally good workplace infection prevention and control measures and high rates of dilution ventilation, brief opportunities for close proximity and prolonged interpersonal contact may permit interpersonal exchange of respiratory aerosols to an extent sufficient to induce asymptomatic or mild infection by SARS CoV- 2 .

\section{REFERENCES}

1. De Souza, M., Russell, A. (2020, May 26). 1 dead, 24 Maple Leaf Foods employees infected with COVID-19 at Montreal plant. Retrieved June 11, 2020, from https:// globalnews.ca/news/6948106/maple-leaf-foods-montrealcovid-19.

2. Fedor, T. (2020, May 05). Cargill processing plant with more than 900 COVID-19 cases reopens despite union opposition. Retrieved June 11, 2020, from https:// calgary.ctvnews.ca/cargill-processing-plant-with-morethan-900-covid-19-cases-reopens-despite-unionopposition-1.4923455.

3. Maple Leaf Foods. Update on COVID-19. (n.d.). Retrieved June 11, 2020, from https://www. mapleleaffoods.com/news/maple-leaf-foods-update-oncovid-19.

4. Grant, T., Baum, K. (2020, June 03). Ontario farms struggle to contain COVID-19 as migrant workers test positive. Retrieved June 11, 2020, from https://www. theglobeandmail.com/canada/article-ontario-farmsstruggle-to-contain-covid-19-as-migrant-workers-test.

5. ASHRAE (2019). Ventilation for acceptable indoor air quality: ANSI/ASHRAE standard 62.1-2019. Atlanta, GA: American Society of Heating, Refrigerating and AirConditioning Engineers. 
6. Lauer, S. A., Grantz, K. H., Bi, Q., et al. (2020). The Incubation Period of Coronavirus Disease 2019 (COVID-19) From Publicly Reported Confirmed Cases: Estimation and Application. Annals of Internal Medicine, 172(9), 577-582. doi:10.7326/m20-0504.

7. Qian, G., Chen, X., Lv, D., Ma, A. H., Wang, L., Yang, N., \& Chen, X. (2020). Duration of SARS-CoV-2 viral shedding during COVID-19 infection. Infectious Diseases, 52(7), 511-512. doi:10. 1080/23744235.2020.1748705.

8. Brosseau, L. (2020, March 16). Commentary: COVID-19 transmission messages should hinge on science. Retrieved June 11, 2020, from https://www.cidrap.umn.edu/newsperspective/2020/03/commentary-covid-19-transmissionmessages-should-hinge-science.
9. Government of the United Kingdom (2020, June 2). Sero-surveillance of COVID-19. Retrieved June 10, 2020, from https://www.gov.uk/government/publications/nationalcovid-19-surveillance-reports/sero-surveillance-of-covid-19.

10. Rosenberg, E., Tesoriero, J., Rosenthal, E., et al. (2020, May 29). Cumulative incidence and diagnosis of SARSCoV-2 infection in New York. Retrieved June 11, 2020 , from https://www.medrxiv.org/content/10.1101/2020.05.25 .20113050v1

11. Public Health Ontario. (2020, June 10). Daily Epidemiological Summary, June 9 2020. Retrieved June 11, 2020, from www.ontario.ca: https://files.ontario. ca/moh-covid-19-report-en-2020-06-10.pdf. 